\title{
A Study of Students from Academic Programs in British Columbia's Community Colleges
}

\author{
JOHN D. DENNISON, GLEN FORRESTER, GORDON JONES*
}

\begin{abstract}
One of the major features of British Columbia's community colleges has been the university transfer programs which provide the opportunity for students to earn credits towards a university degree. Previous studies have shown, however, that only a small percentage of students from these programs actually transfer to a university. This study was designed to examine the behaviour of those students who complete academic or university transfer courses in a college, but do not continue their study in a university. Data were gathered from approximately 4,000 students from 14 colleges in the 1979-80 calendar year. The results of the study indicate that students pursue academic credit courses primarily for personal development rather than for university transfer. The community colleges provide an intellectual and cultural environment, particularly for mature students who for geographic, educational or socio-economic reasons would not have been able to continue their education beyond secondary school. The study provided an important insight into the changing role of the community college. Originally designed as an institution for college age students to begin university level study, it has become a multi-purpose educational resource for a wide segment of society.
\end{abstract}

\section{RESUME}

Une des principales caractéristiques des collèges communautaires de la Colombie Britannique a été d'offrir à ses étudiants la possibilité de prendre des crédits transférables au niveau universitaire. Des études antérieures ont démontré que seulement un faible pourcentage d'étudiants utilisent cette possibilité et transfèrent à l'université. Cette étude avait pour but d'examiner le comportement des étudiants qui, de fait, se prévalent de la possibilité de prendre des crédits transférables mais qui ne continuent pas leurs études à l'université. Les résultats d'une étude qui fut menée en 1979-80 avec la participation de 14 collèges et 4,000 étudiants indiquent que ces étudiants sont d'abord intéressés à parfaire leur développement personnel plutôt qu'à s'inscrire à l'université. Les collèges communautaires procurent un

* The three authors are respectively working for The University of British Columbia, B.C. Research, and The Vancouver Community College. 
environnement intellectuel et culturel pour les étudiants adultes en particulier qui, pour des raisons de niveau de scolarité, localisation géographique et milieu socio-économique, n'auraient pu continuer leurs études au-delà du secondaire. Cette étude démontre que le rôle des collèges communautaires a changé: conçus initialement pour les étudiants d'âge collégial afin de leur permettre de commencer leurs études universitaires, les collèges communautaires sont maintenant devenus une ressource utilisée par un large segment de la société pour des fins variées.

\section{INTRODUCTION}

In 1965, the first community college in British Columbia, Vancouver City College, commenced operation under the aegis of the Vancouver School Board. In the ensuing fifteen years, fifteen colleges have been established throughout the province. Six are located in the densely populated areas of the Lower Mainland and southern Vancouver Island, while the remaining nine are spread over the interior and northern regions of the province. Largely modelled upon the multipurpose two-year institutions in the United States, British Columbia colleges have embraced a comprehensive curriculum, reflected in a variety of programs including university transfer, career/technical, vocational, remedial and upgrading, and community education.

While the colleges have undergone a process of evolutionary change, the university transfer or liberal studies programs have retained a high public profile and are one of the most attractive features, particularly for students who, for a variety of reasons, are unable to enroll in the universities. All three public universities in the province are located in the Lower Mainland - Southern Vancouver Island region. In October 1978, the community colleges in British Columbia enrolled a total of 55,000 students in credit courses of which 18,700 were undertaking academic or "university transfer" programs.

Given the original requirements of the colleges to establish academic credibility, a great deal of effort was made to monitor the performance of students who had transferred from the colleges, with advanced credit, to the universities (Forrester, Jones \& Dennison, 1981). However, it became evident that the proportion of students actually transferring to the universities was quite small, although there has been considerable conjecture as to the percentage which met this category.

In any event, many observers have expressed concern about the effectiveness of university transfer programs in colleges. Reactions range from those who feel that the small number of transfers represents a failure on behalf of the colleges, to others who insist that the figures indicate that the colleges are performing a worthwhile task in helping students to make realistic decisions with regard to their academic futures. However, there is a body of opinion which insists that the notion of "university transfer" is really a misnomer, in that many students 
have no intention of moving to university and are undertaking academic courses for a variety of other reasons.

In view of the debate concerning the university transfer programs and the importance placed upon them, it seemed appropriate to undertake an empirical study in the form of a "follow-up" of those students who, after enrolling in academic programs, did not transfer to university. The foregoing concerns prompted this research project.

\section{STUDY OBJECTIVES}

The objectives of the study could be classified under two categories:

1. To determine the transfer rates to university of students in academic programs, by college, after a period of one calendar year.

2. After identifying those students from the original population not enrolled within the British Columbia educational system after one year, to gather information from them which would provide data on the following questions:

(a) What was their original objective for enrolling at a college?

(b) To what extent had their original objective been attained?

(c) What was the major program of study at college?

(d) What expectations did these students hold for a college education?

(e) If, and for what reason, the student withdrew from the college?

(f) For what reason did the student not continue his education at a university?

(g) What was the student's current activity (either in work or study)?

(h) Would the student re-enroll in college and under which conditions?

(i) Did the student leave the geographic area of the college to find employment?

(j) To what extent did the college education help in obtaining a job?

(k) What was the student's general assessment of his college experience?

Students were also invited to comment on any unspecified topic in an open section on the questionnaire.

\section{METHODOLOGY}

The procedure followed in the project was finalized after a series of meetings with representatives of the Colleges, the Ministry of Education and the Academic Council, the latter being a provincial committee of educational professionals and the lay public created to coordinate academic programs within the college system. The population base for the study was defined as all students enrolled on either a part or full-time basis, in both first and second years of the academic or "university transfer" programs in all fourteen community colleges in British Columbia as of September, 1978.

The September 1979 enrolment files of all colleges, universities and the British Columbia Institute of Technology in the province were matched by 
student names and birthdates with the original population base to determine which students had transferred to other institutions during the intervening twelve month period, and which students were still enrolled in their original colleges. This procedure provided data on transfer rates which were based upon the follow-up of individual students, rather than through the more usual and less accurate technique of comparing gross enrolments.

From the original base population of 17,181 students, 2,168 were identified as having transferred to one of the universities, 290 had transferred to another college or to the British Columbia Institute of Technology. In addition, 3,897 students were still enrolled in their original institutions. The remaining 10,883 students were regarded as "educational status undetermined" or, by the definition of the study, "non-transfers". These students had not been found among the September 1979 enrolment files in British Columbia and became the "target" population for the remainder of the project.

The procedure then involved contacting these non-transfer students by means of a questionnaire, designed to meet the objectives of the study. Mailings were done in February 1980, approximately nine months after most of the students would have last attended their college. The students were classified by college originally attended and were all mailed a questionnaire, in the case of the small colleges, or sampled by a stratified formula, in the five larger colleges. In total, the sample selected from the target population comprised 7,997 students (represented a $70 \%$ sample of the target population). By the final date for return of the questionnaires a total of 3,923 responses had been received. The actual rate of usable returns was $49 \%$. However, 935 mailings were reported by the Post Office as undeliverable. Adjusting for these undeliverable mailings raises the return rate to $56 \%$, a figure more indicative of the degree of participation and cooperation received from former students. On a college-by-college basis the response rates ranged from $40 \%$ to $65 \%$. A total of 871 respondents completed the section of the questionnaire which invited open-ended comments and reactions. These comments were studied, classified and incorporated into the results and conclusions of the study.

After the response forms had been key-punched, a broad statistical analysis of the data was conducted. In each case, significant statistical differences were noted and the results processed to record such differences. A comparison of the respondent population with the target population was made on the basis of age and sex. The Chi square tests ${ }^{1}$ revealed some statistical bias in terms of females and adult students, both categories having responded more frequently than males and college age students. A large number of multi-variate tables were produced, based upon observations drawn from previous studies.

\section{RESULTS}

\section{Transfer Rates}

Table 1 summarizes the September 1979 enrolment status of students from the September 1978 base population. The transfer rates to British Columbia univer- 
TABLE I

a North Is land College did not participate in the study and is therefore not included in the totals.

Est imate derived from students responding to the follow-up survey who indicated that they were currently enrolled at a university. The specific university was not identified and may well be outside the province in many cases. Since these figures reflect only those students responding to

Figures in parenthesis are adjusted rates, calculated by eliminating those students who were still enrolled at their original college. 
sities, by college, range from $5.6 \%$ to $17.1 \%$. The adjusted transfer rates, calculated by eliminating the students still enrolled at their original college, are indicated in parentheses.

Adjusted transfer rates, to British Columbia universities, by college, range from $6.4 \%$ to $21.4 \%$. With respect to the terms of the study, the percentage of the "nontransfer" or target population students ranges $56 \%$ at Capilano to $82 \%$ at Northwest College.

Before drawing conclusions from the data in this table the consequences of the following important caveats should be noted.

Enrolment status in September 1979, as defined in the study, includes only those students enrolled in academic programs in selected public tertiary institutions in British Columbia. It would not include students continuing their education in the five specialized technical institutes of the province other than the British Columbia Institute of Technology, in private institutions or in career/technical or vocational programs of the community colleges. Generally, it will also not include students continuing their education outside the province, with the exception of those enrolled in universities who managed to receive the follow-up questionnaire and chose to respond. Corrections for this latter group were made as noted in footnote "b" of the table. Consequently, transfer rates listed in this table should be viewed as under-estimates.

The time frame of the data was only one calendar year, September 1978 to September 1979. Presumably, many students may enroll or re-enroll in various educational institutions after spending undetermined periods of time in other activities.

The "non-transfer" population includes students who have withdrawn from their programs at various times during the year as well as students who may have completed one or more semesters of study at the college.

It may be argued that many students enrolled in a college in September 1978 would not be eligible for transfer to a university in September 1979, particularly if they were part-time students. There is no way of addressing this possibility. However, some students could conceivably transfer after only one course at college, depending upon their academic status.

\section{Questionnaire Results from "Non-Transfer" Students}

The majority (62\%) of students in academic programs enroll on a part-time basis (Educational Data Services, 1979, p. 27). In the last ten years this proportion has doubled (Dennison, 1978, pp.27-28). Questionnaire results from the "nontransfer students" indicated an identical $62 \%$ part-time enrolment status. Two thirds of the female students were part-time, while only half of the males were enrolled in that category. It was also found that over $83 \%$ of the mature students and $38 \%$ of the college age group were part-time. In other words, the results showed a high relationship between age, sex and part-time study.

Thirty-four percent of the "non-transfer" students reported transfer to 
university as their original reason for enrolling in college. Twenty-five percent gave their prime reason as "personal enrichment" and smaller percentages chose "learning new skills" and "undertaking a career". In the case of mature students, only one in five indicated that they intended to transfer to a university.

Social sciences and humanities proved to be the most popular areas of study, particularly for mature students. Further analysis showed that the goal of "personal enrichment" was related to the choice of fine arts, languages and humanities as fields of study at college. Students who indicated that their original objective was university transfer were more frequently enrolled in the sciences.

Prominent factors in the choice of a community college over other institutions included proximity to students' homes $(68 \%)$, low cost $(50 \%)$, programs available $(43 \%)$, and the fact that the "college was there" (32\%). Educational factors such as teaching reputation (14\%) and intellectual environment (9\%), were apparently less important in making the choice.

The reasons for not transferring to university are varied and complex. Personal factors such as "never intended to transfer" (20\%), and certain negative views of universities were more frequent than more practical difficulties as cost (12\%), grades $(3 \%)$, or inadequate prerequisites $(6 \%)$.

The data indicate that almost two thirds of the students were working full or part-time. In fact, the proportion of involuntary unemployed students was less than $6 \%$. The majority of jobs held by the ex-students were in the "white collar" or semi-professional categories. A number of students from several colleges move from their home communities to find jobs. Not unexpectedly, this behavior was more evident from students in more isolated regions in the province, where up to $25 \%$ relocated.

Apparently a college education was not an important factor in obtaining a job. Only about $17 \%$ of the students claimed that their employers expressed a specific interest in their college performance. As the education taken by these students was academic, rather than vocationally oriented, the foregoing observation about employers might have been anticipated. Although the subjects in this study had enrolled in non-vocational programs of study at college there were several indications that the practical issue of employment was prominent in their minds. When asked to indicate their views of the most important objectives of post-secondary education, the single greatest percentage chose "knowledge and techniques applicable to a vocation or field of special interest" (54\%), over more intellectual objectives such as "critical thinking" (16\%).

Furthermore, asked to express the factors which would influence their decision to re-enroll in college, a substantial percentage $(18 \%)$ stated "potential benefit to employment". In fact, over one third of the respondent group would choose a career, technical or vocational program on re-enrolment at college.

One question asked respondents to react to certain traditional goals of a college education and to indicate whether the goals had been attained. In terms of goals, students placed greatest value upon obtaining a general education and in preparing for a career. However, while many respondents claimed a high success 
rate in obtaining a general education $(50 \%)$, less than one third indicated that they were prepared for a new career.

Finally, in assessing various statements regarding their college experience, students were strongly supportive of the fact that colleges provided increased opportunity for study, were readily accessible in academic, financial and geographical terms, and offered reasonably sized classes with a "positive" mix of students (age, background). However, they were less convinced that the quality of teaching was high, that colleges were concerned about student needs and in the quality of counselling services.

\section{Written Comments from "Non-Transfer" Students}

The large number of voluntary responses to the "comments invited" section of the questionnaire suggested that many students were anxious to express some personal reactions and appreciated the opportunity provided. This view was supported in the comments. In summary, about $60 \%$ of the comments would be regarded as complimentary to the colleges, about $30 \%$ critical and the remainder ambivalent.

The subjects of the comments concerned teaching, counselling and "standards". Expectations in these areas were apparently quite high and students reacted strongly to their experiences. Frustrations were expressed with regard to finances, day-care facilities, inconvenient course scheduling, lack of facilities to continue their education beyond college and the problems associated with "moving to the coast".

The most intriguing aspects of the comments were to be found in the characteristics of the responding population. It seemed that colleges had touched the lives of students from every conceivable socio-economic group, occupational area, age, aspiration and reasons for attending college.

\section{IMPLICATIONS AND CONCLUSIONS}

The data produced by the study are open to several interpretations, depending upon one's understanding of the role and function of the community college in the broad spectrum of post-secondary education. While it is difficult to completely eliminate speculation, there is sufficient evidence from this research to indicate that the following comments have validity, and, as such, deserve the attention of the college community.

\section{Transfer Rates}

With regard to transfer rates, which reflect the flow of students through the post-secondary educational system, any conclusions must be drawn in the light of the caveats noted earlier in the paper. Although the college transfer rate to university, on a provincial basis, was approximately $16 \%$, this must be assumed to be a conservative figure. It is important to remember that this rate represents the behavior of students in only one calendar year. Further, the range of transfer 
rates among colleges was considerable. Clearly, some colleges in the province are more "transfer oriented" than others. These include the "established" interior institutions and the large lower mainland colleges. On the other hand, the "new" colleges, most of which are located in relatively isolated communities, seem to serve students with different priorities.

Whether one regards the relatively low provincial rate of transfer by colleges to universities as acceptable or not must rest ultimately with one's philosophy towards community colleges. To some, the figures indicate that the colleges are performing an important task in helping students select realistic goals. To others, the same statistic suggests more serious implications, not the least of which is financial.

\section{The College Academic Programs}

The study reinforced a fairly common hypothesis, which has been advanced on previous occasions in the literature, that the notion of "university transfer", as applied to the academic programs in the community colleges, is largely a misnomer. Evidently, students pursue academic credit courses more for their potential value and possible future use than for immediate transfer to other institutions. Not only did many students express the view that transfer to university was not their primary goal, but several comments reflected the difficult conditions under which they pursued their education, clearly making transfer to university a most improbable circumstance.

Comments from students indicated a variety of socio-economic factors, family circumstances and geographic isolation which affected students' educational mobility. It was evident that in many cases the college experience had had a significant impact upon their lives. To other students, however, the colleges for one reason or another had proven to be a disappointment or an unrealized opportunity. Even for many students who had made a successful re-entry into the learning environment, the college was effectively a terminal educational experience. Students in rural areas in particular found that degree completion at a university was an unrealistic or impractical goal.

The study gave credence to the view that colleges provide academic courses and programs for large numbers of students for almost as many reasons as there are students. In this respect, the colleges' long-standing commitment to the academic component of the curriculum is both defensible and desirable. The comments and responses to the questionnaire items might well be interpreted as being in contradiction to those who view colleges essentially as institutions for the provision of vocational and technical training. It is obvious that, to many, the college is a source of intellectual stimulation which is locally available and hence represents an alternative to the virtually inaccessible university.

There has been considerable reference in the discussion of results to the apparent anomaly connected with the notion of "university transfer" courses, in view of the stated intention of a large percentage of the students who enroll in them. Presumably, if many students take these courses for personal enrichment, the 
features of university transfer courses such as examinations, grades and formalized instruction would be of little concern. It was suggested in the students' comments that colleges might recognize the problem by being less concerned with the "transfer credit" factors and more with general education. At the same time, it is recognized that experience in this regard has been of little value. Colleges have had limited success, in the past, with "general" academic courses which do not carry university transfer credit. For some reason, students have shown little interest in these courses. Comments on the questionnaires which were directed at "standards" were supportive of raising, rather than relaxing, the quality of the courses. Apparently, students expect and desire high standards.

Given all of the foregoing, colleges are faced with a considerable dilemma in how to approach academic courses for a most heterogeneous student clientele. The concerns of the universities must be recognized, as must student expectations and faculty expertise. It seems that the only satisfactory answer lies with continued negotiation at the individual academic discipline level. Experience in the United States (MacLaren, 1978), indicates an evolving autonomy for the colleges while, at the same time, retaining the confidence of the universities.

One apparent contradiction which emerged in the results was that which existed between students' stated views of the objectives of enrolling in postsecondary education and the type of program in which they actually enrolled. While the majority indicated that vocationally related knowledge was of primary value, these students were enrolled in academic programs. There are a number of possible explanations for this phenomenon. Presumably, jobs are of concern in the long term for most students, whether they at tend college or university. However, a general academic curriculum is considered complementary, rather than contradictory, to this objective. In this context, student behaviour is understandable.

There is some indication that several students had enrolled in career or vocational programs after their initial venture into academic education. Others might well have not been able to enroll in the program of their choice immediately and had taken the academic program while waiting for the opportunity to eventuate. Either way, the most appropriate conclusion to draw is that, irrespective of students' intentions with regard to a vocation, and academic program of study remains an attractive experience, particularly under the conditions provided through community colleges.

\section{The College Students}

Another often repeated assumption supported by these results was that an increasing percentage of mature, part-time and female students were enrolling in community colleges. It was possible to compare some of the demographic data with similar statistics available in the literature (Educational Data Services, 1979, p. 74). Since 1972, the increase in proportion of part-time students has been impressive. As there is a predictive relationship between part-time study with 
age and sex, the proportion of the last two variables increased correspondingly. While these results are not surprising, they do dramatize the evolving character of the college student population and suggest a need for colleges to adjust their priorities accordingly.

A further relationship deserving comment is that which exists between demographic variables and reasons for attending college. Personal enrichment is a prime goal of older students and colleges might bear this fact in mind in timetabling and course planning. In periods of financial constraint, institutions tend to limit the number of courses in less traditional time slots. This practice ignores the realities of the changing student population. However, if the trend of the past few years continues, and there seems to be no reason why it should not, colleges will have to make even greater adjustments to accommodate the changing student clientele. These adjustments may include more non-traditional course scheduling and decentralized facilities.

One statistic regarding the accomplishment of students' original objectives in attending college is worthy of particular note. Of those students who indicated their intention as being either one or two years of preparation for university transfer, approximately a quarter noted that they had changed their original goal for one which was more "appropriate". A similar percentage was found in those who stated that they came to college to determine their vocational interest. In both cases, it may be concluded that the college has played a role in helping students make decisions regarding their academic or vocational futures. While this particular function of the colleges has been documented by Clark (1960), there has been limited evidence of its success. For the colleges in British Columbia, at least, there is now some indication of their role in this regard.

To some extent, the study results. contradict a minority view that college students, particularly those in academic programs, are perpetual students who are not, or never intend to be, gainfully employed. While the follow-up mailing was approximately nine months after the students' last enrolment in the college, the employment rate was quite high. Only $6 \%$ were job seeking and $2 \%$ were "unemployed", figures which were somewhat below provincial rates. While it is true that some respondents were still full or part-time students, the overall record of employment is impressive. It might be concluded that those who seek education after compulsory schooling are also those who contribute to the workforce. In one sense, it could be argued that much of the cost of their education is borne through the taxes generated from their own earnings.

With respect to the kinds of jobs held by former college students "white collar" occupations such as clerical, professional, sales, and managerial predominate. While it is tempting to coincide that former students hold such positions because of their college education (although there are certain contradictions to this argument provided in other data), this conclusion must be reserved. It may well be that the same variables, motivation, intellectual curiosity and energy, contribute both to an individual's determination to attend college and his ability to hold certain positions in the work force. 


\section{The College Concept}

When the community college concept was being developed in British Columbia, the rationale for their establishment was based upon a number of essential criteria. Included in the latter were low cost, location within commuting distance in their region, reasonably open admission policy, comprehensive curricula and quality teaching and counselling. The data gathered in this study tend to reinforce the conclusion that colleges have been successful in meeting many of the original criteria. Certainly, cost and geographic accessibility were primary incentives for enrolment in the greater proportion of their clientele in academic programs. However, the teaching reputation of the college and the perception of an intellectual environment attracted a smaller percentage of students. This view was reinforced by the comments which were offered on the questionnaire. Teaching and counselling met with mixed assessments by former students. While there were many who expressed considerable admiration for these two features, there were several critical comments.

It follows that colleges should spend more time and make greater efforts to ensure quality teaching and counselling. Institutions established with high priority upon these aspects of their operation cannot afford to allow indifferent or mediocre performances by their faculty. Judging from the responses to the questionnaire, students react strongly to unsatisfactory experiences with teachers and counsellors. This conclusion underlines the vulnerability of the faculty and dramatizes the challenges of college teaching.

The data gathered in the study does support the view that there exists a reasonably large number of students who, often for geographic reasons, are unable to complete a university degree and are somewhat frustrated after a successful college experience. The wide dispersal of these individuals through the province suggests the potential value of opportunities available through distance learning techniques.

There was some evidence in the data to support the view that involvement in post-secondary education is positively related to the existence of a college in the region. Previous studies (Angus, 1979; Dennison, 1978; \& Dennison et al., 1975), have indicated that participation rates are higher in such areas. In this study, the responses to the category "college was there", as an option in reporting important factors in the choice of a college, were in excess of $30 \%$. In addition, students from "non-commuting" colleges, i.e. beyond range of a university, responded at a rate of almost $50 \%$ to this option. While the term "college was there!" may be regarded as non-specific, it undoubtedly summarized the reason for college attendance by a large number of students. While open to several interpretations, the data does tend to support the relationship noted above.

\section{A FINAL COMMENT}

The data gathered in this study reinforces certain assumptions about community colleges and the students which attend them and opens others to question. Of 
more importance, however, the study exposed a behaviour pattern in society, related to education that is in a state of evolution. Clearly, there were specific differences in the characteristics of college students from those found in other studies conducted as recently as five years ago. These differences are both demographic and attitudinal. (Dennison, et al., 1975).

If colleges, universities and other institutions of post-secondary education are to respond effectively to a changing clientele, it is imperative that they be cognizant of the quality of the change and the degree to which it is occurring. For these reasons, it seems essential that efforts be made to monitor the system accurately and regularly, to base policy and practice upon real, rather than assumed data, and to reinforce the impression that the views of the broad community, including students, employers and taxpayers, are considered in the process.

In the context of the above, this particular study is a first step.

${ }^{1}$ The significance levels of $x^{2}$ test results by college on the basis of sex ranged from 0.005 to 0.61 with the province total being 0.00 . On the basis of age the significance levels ranged from 0.03 to 0.82 with the province total again being 0.00 . Thus, using a 0.05 level of significance criterion, there appeared to be no statistical non-response bias on the basis of age and sex at the provincial level. However, at the individual college level most of the smaller colleges had statistical bias while the larger ones did not.

Note: Copies of the questionnaire used in the study and the detailed responses to each item are available from the authors upon request.

\section{REFERENCES}

Angus, F. Trend analysis of enrolments and participation percents in British Columbia postsecondary education 1967.1978. Vancouver, Canada: B.C. Post-Secondary Education Enrolment Forecasting Committee, 1979, Report 31.

Clark, B.R. The cooling-out function in higher education. American Journal of Sociology, $1960,65,35-38$.

Dennison, J.D., Tunner, A., Jones, G. \& Forrester, G.C. The impact of community colleges: a study of the college concept in British Columbia. Vancouver, Canada: B.C. Research, 1975.

Dennison, J.D. University transfer programs in the community-college. The Canadian Journal of Higher Education, 1978, 8, 27-36.

Educational Data Services. B.C. post-secondary statistics: enrolment data 1978-79. Victoria, Canada: British Columbia Ministry of Education, 1979, Publication No. 200.

Forrester, G.C., Jones, G. \& Dennison, J.D. Trends in university achievement: 1976-1979. Vancouver, Canada: B.C. Research, 1981, B.C. Colleges Articulation Study Report 42.

MacLaren, S. Community college - university relations: an examination of the positive functions of conflict. Oklahoma State University, Stillwater: Council of Universities and Colleges, 1978, Occasional Paper Number 1. 